\title{
La Organización Social de Salud de Médicos Indígenas Tradicionales y la crisis de la tradición Tének de la Huasteca potosina
}

\author{
DANIEL FLORES ALBORNOZ
}

A partir del estudio de caso de una organización de médicos indígenas tradicionales de Aquismón, San Luis Potosí, en este artículo se muestra cómo la tradición Tének se encuentra en crisis. Se argumenta cómo la intención reivindicativa de una tradición, en un contexto en el que los lenguajes que están en juego y sus prácticas sociales contradicen la tradición que se busca rescatar, genera una crisis difícil de solventar. El análisis ilustra el surgimiento de la crisis, que descansa en los intereses de las instituciones del Estado con las cuales se mantiene cierta oposición, así como con otros curadores indígenas que no siguen la tradición, por lo cual la crisis no sólo no se resuelve, sino que se acentúa y prevalece.

PALABRAS CLAVE: organización de médicos indígenas tradicionales, confusión social y cultural, tradición indígena en crisis, Huasteca potosina, curanderismo

The Health and Traditional Indigenous Medicine Social Organization and the Crisis of Tének Tradition in the Huasteca region of San Luis Potosí

Based on the case study of an organization of traditional indigenous physicians located in Aquismón, San Luis Potosí, Mexico, this article shows the crisis of the Tének tradition. We argue how the reclaiming intention of a tradition generates a crisis difficult to solve, in a context where the languages involved and their corresponding social practices contradict the very tradition to be defended. The analysis illustrates that the emerging process of the crisis rests in the interests of the State institutions, against whom some opposition remains as well as other indigenous healers who do not follow the tradition, so the crisis is not solved but accentuated and prevails.

KEYWORDS: traditional indigenous healers organization, social and cultural Egresado del doctorado en antropología confusion, crisis of indigenous tradition, Huasteca of San Luis Potosí, quackery 
or iniciativa del Instituto Nacional Indigenista (INI), hoy Comisión Nacional para el Desarrollo de los Pueblos Indígenas (CDI), en México se crearon organizaciones de médicos indígenas tradicionales, llamadas así por la institución y cuya denominación adoptaron los curadores indígenas organizados en la actualidad, como los de Aquismón, San Luis Potosí, en la región Tének de la Huasteca. ${ }^{1}$ La disposición del INI se llevó a cabo casi de manera paralela al plan del Estado de instalar clínicas y brigadas médicas en zonas marginadas a lo largo de la historia. Las investigaciones antropológicas que tomaron como objeto de estudio la salud y la enfermedad en el marco de cosmovisiones indígenas son anteriores al esfuerzo generalizado del Estado, en particular al Programa de Solidaridad Social por Cooperación Comunitaria, creado en 1979 mediante un convenio entre el Instituto Mexicano del Seguro Social y la Unidad de Coordinación General del Plan Nacional de Zonas Deprimidas y Grupos Marginados — constituida en 1977—, conocido como IMSS-Coplamar.

Los documentos podrían llevarnos hasta fray Bernardino de Sahagún (1829) o los atisbos de Carl Lumholtz (2017), aunque fue durante la segunda mitad del siglo Xx cuando el tema salud/enfermedad entre poblaciones indígenas adquirió interés entre antropólogos, como un tipo de especialidad dentro de la disciplina. Varios autores registraron aspectos de lo que ahora se conoce como medicina tradicional mexicana, aun cuando el concepto "tradicional" es ambiguo y hasta equívoco en ciertos contextos y enfoques analíticos (Menéndez, 1981; 1987; 1994). El esfuerzo

1 Este artículo recoge datos etnográficos de Aquismón, obtenidos en trabajo de campo, de agosto de 2013 a julio de 2014. Es parte de un capítulo de Flores (2017). La palabra tének designa al pueblo indígena que habla la lengua del mismo nombre. El pueblo Tének es heredero de los antiguos huaxtecos, cuyos vestigios se estudian en proyectos activos de investigación arqueológica. De este pueblo proviene el nombre de la Huasteca que conocemos hoy. En algunos trabajos, se escribe teenek, lo cual se ha convertido en una convención académica. Durante el trabajo de campo, dos interlocutores comentaron que te'en, y su variante te'enal, con dos vocales, significa que alguien "acaba de reírse". He decidido utilizar la palabra con una vocal y con tilde porque la pronunciación sugiere que es una palabra llana, es decir, con acento prosódico en la penúltima sílaba, y porque este documento está escrito en español. El empleo de la mayúscula hace referencia a un pueblo indígena heredero de una historia cultural de importancia, lo que lo hace un nombre propio. 
por documentar el tema de salud/enfermedad entre grupos indígenas de México, no obstante, representa un acercamiento importante a una serie de conocimientos y prácticas que, reprocha Aguirre Beltrán (1987), pasaron inadvertidos en el diseño del IMSs-Coplamar, que no consideró el criterio antropológico.

La antropología sobre salud/enfermedad y sus formas de atención entre grupos indígenas daban pistas claras para una posible articulación de saberes que ayudaran a implementar mejor los programas gubernamentales de salud pública en zonas marginadas. En 1955, Aguirre Beltrán publicó Programas de salud en la situación intercultural (1994) y tres años después George Foster dio a conocer su libro Problems in Intercultural Health Programs (Foster, 1958). Siguieron estudios de autores ahora clásicos, como Villa Rojas (1992) o López Austin (1989), entre otros, paralelos a la ejecución del IMSS-Coplamar, pero el programa no contempló el criterio antropológico en el arranque o el proceso de implementación.

Antropólogos y afines, con ayuda del INI, tomaron como intención política que los curadores indígenas tuvieran presencia y voz en los procesos de atención de la salud pública. Se estimó que los saberes locales se consideraran en los planes de expansión de los servicios públicos de salud que operan bajo el modelo científico de sociedades industriales. La operación de programas externos, no obstante, se inclinó por subcontratar u organizar a gente de las comunidades en faenas de mano de obra para la construcción de caminos, centros de salud, etc. El INI también fue un puente para que profesionistas de varias disciplinas se instalaran en regiones con población numerosa y muchas veces indígena. Existía, pues, un grupo de indigenistas entusiastas que buscaban abrir espacios de reconocimiento a los saberes y prácticas indígenas, pero el papel de las instituciones fue ambiguo.

Destaca, por ejemplo, el primer Congreso Indígena en San Cristóbal de Las Casas, Chiapas, en
1974. La participación de curadores indígenas en el evento logró promover lo que ahora se conoce como la Declaración Tzotzil de Salud, en la que se aboga por el respeto a la diversidad cultural y el reconocimiento de saberes y conocimientos al margen del lenguaje de la ciencia médica (citada en Lozoya y Zolla, 1983: 11). Esto dio pie a la organización de curadores indígenas, y a su vez, a la regulación de su operación en los términos legales establecidos por el Estado. Curanderos, hueseros, sobadores y parteros de varios municipios de Chiapas fueron de los primeros en establecer una agrupación de carácter jurídico con reconocimiento del INI y otras entidades, la Organización de Médicos Indígenas del Estado de Chiapas, A. C. (OMIECH), en 1984. Poco a poco, las experiencias se multiplicaron en el país, pero el reconocimiento formal sólo se otorgó a las parteras empíricas que recibieron capacitación en alguna institución pública de salud (Campos, 1996).

Para ganar mayor reconocimiento, académicos interesados en el tema jugaron un papel protagónico y firmaron un convenio de colaboración con la OMIECH, en 1988 (Freyermuth, 1993). Después, el gobierno del estado contribuyó para crear el Museo de la Medicina Maya, en el que se observa una exposición botánica y algunos rituales de curación, mientras los médicos de la OMIECH ofrecen curaciones y administran una farmacia herbolaria. El trabajo dentro de un espacio museográfico devino en la adaptación a un recinto público de prácticas que por lo regular se realizan en espacios privados, lo que supone una alteración de las formas más tradicionales de la medicina indígena:

El visitante del Museo de la Medicina Maya ha dejado atrás la cultura pasada y ahora se encuentra de cara a la auténtica medicina tradicional moderna. [Se privilegia] el uso racional de remedios que tienen un efecto farmacológico comprobable por exámenes de laboratorio. La medicina local herbolaria se ha resignificado al interior del paradigma 




LUCY NiETO • Paisajes en la Huasteca, octubre de 2011.

científico. [Es una] medicina herbolaria, mucho más avanzada y "moderna" que las prácticas de tipo chamanístico (Ayora, 2002: 162).

Las adaptaciones varían según la región, pero son efecto de la iniciativa del INI de creación de espacios de salud comunitaria en los que curadores indígenas ofrecen atención al público. Algunos organismos, como el IMSs, aprovecharon los encuentros y la formación de agrupaciones para levantar un censo, que resultó en la participación ocasional de algunos curadores indígenas en lo que hoy la CDI llama hospitales mixtos, y los espacios de intercambio de saberes se inclinaron hacia la experiencia de médicos alópatas. En el caso de Chiapas, como documenta Freyermuth (1993: 104), el saber científico del médico alópata percibe el saber indígena tradicional como un no saber. A su vez, los curadores indígenas no siempre están dispuestos a participar en capacitaciones del sector salud. Muchos temen que se les califique como personas que carecen del don de curar por utilizar técnicas como escuchar la sangre por medio de la pulsación. Se trata de una relación de poder en la que se impone la ciencia médica y se genera lo que Zolla (2011) llama la "interculturalidad asimétrica".

En el proceso de conformación de organizaciones se creó el Consejo Nacional de Médicos Indígenas Tradicionales (Conamit), también impulsado por el INI. Durante su existencia, aproximadamente de 1991 a 2007, sirvió como órgano rector de las asociaciones de médicos indígenas tradicionales en 
el territorio nacional, por medio de foros y debates en torno a las políticas de reconocimiento, entre otros temas. Retomo la historia particular de la Organización Social de Salud de Médicos Indígenas Tradicionales (OSSMIT) como punto de partida para analizar la crisis en que se encuentra la tradición Tének, la falla conceptual del sincretismo y la diferencia entre los médicos indígenas tradicionales organizados y el curanderismo al margen de una organización.

\section{La creación de la ossmiT y sus fundamentos legales}

En algunas reuniones nacionales del Conamit participó Miguel Ángel Calixto, presidente y fundador de la ossmit. Como médico indígena tradicional reconocido por el Consejo de Ancianos Indígenas de la región Tének y náhuatl de San Luis Potosí, y su experiencia en cargos tradicionales, es una figura importante en la promoción y defensa de las costumbres y tradiciones indígenas. $\mathrm{Su}$ asistencia a encuentros nacionales del Conamit le ayudó a mantener la iniciativa de la OSSMIT, un referente importante para entender a los médicos indígenas tradicionales organizados. La OSSMIT se fundó entre 1970 y 1975, cuando Miguel empezó a curar de manera formal y se asoció con otros curadores de la región. Ya en funcionamiento, adquirió su registro como asociación civil en 1994. Desde entonces, los miembros fundadores y médicos indígenas tradicionales que se han sumado a la iniciativa han celebrado reuniones. Así se constituyeron el consejo interno y el Consejo de Médicos Indígenas Tradicionales del Estado de San Luis Potosí (CDMIT): “conforme a las tradiciones y mandamientos que conceden los artículos 9o. y 4o. de nuestra Constitución mexicana para la defensa y protección, rescate y desarrollo de la medicina tradicional indígena, para su preservación así a las futuras generaciones".
Con esta referencia de acción dentro de un marco legal, el CDMIT consideró mantener objetivos y metas elaborados por consenso, que a la letra dicen:

- La misión y cosmovisión [es] salvaguardar nuestra propia cultura de nuestros pueblos antiguos indígenas, en buena armonía con las autoridades civiles y militares.

- Rescatar nuestro mundo antiguo que es testamento y patrimonio histórico, herencia que nos han dejado nuestros antepasados.

- Rescatar y defender nuestras artes, costumbres y tradiciones para hacerlas prevalecer a través de los siglos, que es herencia para nuestros hijos, nietos y futuras generaciones.

- Cuidar nuestra lengua materna, nuestra medicina tradicional, nuestra música y danzas indígenas, nuestros bailes, nuestras artesanías, nuestra indumentaria tradicional, nuestros medios ecológicos, nuestros montes, manantiales y fauna silvestre, velar por la salud de nuestras comunidades y su bienestar, por la educación de nuestros hijos así como también por su salud, en materia jurídica defender nuestros derechos de las injusticias.

- Aclaramos y declaramos que esta organización es netamente indígena no lucrativa.

- Aclaramos y declaramos que nosotros los indígenas no tenemos fronteras, así como somos respetuosos, tanto de las corrientes políticas como credos religiosos.

- Respetuosos también de la medicina académica o institucional.

- Respetuosos de las leyes que rigen nuestro país.

- Por el presente y futuro de las Etnias de San Luis Potosí, para que perduren a través de los siglos.

- Por el presente y futuro de los pueblos indios de México. $^{2}$

Lonas colgadas en las paredes de la sede de la ossmit, en la cabecera municipal de Aquismón. 
La posición de la OSSMIT en el CDMIT es con claridad de carácter político, pero dirigida hacia el interior más que hacia el exterior de la organización. Se busca ordenar conductas y valores que forman parte del deber ser indígena. El fundamento legal parte del mandato constitucional de preservar costumbres $y$ tradiciones, y del derecho legítimo de los acuerdos tomados en asamblea, con carácter jurídico y autónomo. Se exhorta a ser indígenas en un marco de valores que se comprenden como elementos permanentes a lo largo de los siglos pasados y futuros. Para ello hay que defender y preservar los conocimientos y formas de organización propias. Se reconoce la existencia de la medicina científica y un marco jurídico nacional, pero se señala una distinción entre "ellos" y "nosotros".

Esta diferenciación es defensiva en esencia. Se argumenta, por ejemplo, no tener fronteras, pero el celo sobre el conocimiento implica erigir algunas. Esto implica la negociación permanente entre lo propio y lo que se puede compartir o no; la búsqueda de reconocimiento externo sin perder autonomía; el reconocimiento del Estado-nación, en el que la herencia cultural ancestral está vigente y debe ser la forma de organización social interna. La distinción ellos/ nosotros es ambigua y en todo caso obedece a la búsqueda constante de una forma de vida.

Los discursos varían según el tipo de negociación, aunque prevalece un lenguaje que da sentido a la identidad, definida en este caso por medio de una organización que se fundamenta en la noción de ser médico indígena tradicional. En la sede de la OSSMIT pueden leerse consignas impresas en lonas usadas en asambleas del CDMIT. Una dice:

La medicina tradicional herbolaria es propiedad de los pueblos originales de México, en esencia y en su espíritu, ha sido desde tiempos inmemoriales, todo sistema místico de salud dentro de su propio universo; es necesario la consolidación de las organizaciones para salvaguardar toda esta ciencia que nos han heredado nuestros antepasados. Se aconseja a todos los médicos indígenas a no divulgar estos conocimientos a gentes extrañas porque es patrimonio de nuestros hijos y nuestros nietos y de las futuras generaciones.

Una posición difícil, a la luz del lenguaje científico en el ámbito nacional, cuando en 1975, alrededor de la fecha de fundación de la OSSMIT, el entonces presidente de la república, Luis Echeverría, fundó el Instituto Mexicano para el Estudio de las Plantas Medicinales (Imeplan), que en 1980 se convirtió en la Unidad de Investigación Biomédica en Medicina Tradicional y Herbolaria, como apoyo del programa IMSS-Coplamar, en la que se realizaron estudios fitoquímicos y farmacológicos a una gran cantidad de plantas autóctonas (Lozoya y Zolla, 1984; Lozoya, 1988). El quehacer científico sobre plantas medicinales continúa; por ejemplo, en una tesis de licenciatura en biología se analizó el efecto insecticida de plantas comunes en la medicina popular de zonas rurales e indígenas de la Huasteca, para combatir plagas en cultivos, como la mosca de la fruta (Drosophila melanogaster) y el gorgojo del maíz (Sitophilus zeamais), para lo cual se tomaron muestras de laboratorio. Se extrajeron aceites esenciales de yerbas utilizadas para dolores e infecciones estomacales, como estafiate (Artemisia ludoviciana), escoba amarga (Parthenium hysterophorus) y cempasúchil (Tagetes erecta), de altamisa (Zalizania triloba), empleada como desinflamatorio posparto, y liquidámbar (Liquidambar macrophylla), de uso sedante. El estudio demostró la posibilidad de crear insecticidas naturales amigables con el ambiente y aplicables a la agricultura: "los resultados obtenidos demuestran que los aceites esenciales de las cinco especies estudiadas presentaron efecto insecticida, validando así las propiedades que la gente atribuye a estas plantas" (Cázares, 2006: ix). Esto es, la población indígena y campesina ya utiliza las especies estudiadas para evitar que el maíz se plague de 
gorgojos, y prepara escobas y aguas para limpiar las habitaciones y evitar la presencia de pulgas y ácaros, entre otros usos (2006: 19 y ss.)

Los resultados con aval científico podrían ser un referente para la producción de insecticidas naturales de patente en el ámbito industrial, pero se corre el riesgo de utilizar un conocimiento que, para la OSSMIT, representa un despojo de los saberes ancestrales indígenas. Para entender su posición, vale la pena preguntarse: ¿qué significa que la medicina herbolaria y tradicional sea de propiedad indígena "en esencia y en espíritu"? La respuesta implica reconocer que existen otras "esencias" y "espíritus". Esta posición ideológica es debatible, pero supone el uso de un lenguaje con reglas gramaticales propias que, en términos de prácticas socioculturales, pueden en efecto marcar una diferencia fundamental que echa por tierra la idea del sincretismo.

\section{El poder de curar desde nosotros, los médicos indígenas tradicionales}

La división de alguna manera imaginada entre "ellos" y "nosotros" tiene un sedimento histórico que sigue vigente:

Nuestros antepasados fueron quemados, torturados, asesinados [...]. No podían hablar la lengua castellana [pero] la inquisición quería que confesaran. Cuánta ignorancia tenían esas gentes que venían [...]. Les decían que se confesaran, que si eran diableros, hechiceros, pero pobres, ellos no sabían ni qué era eso [...] y eran descuartizados, quemados [...]. Todavía en nosotros está sangrando la herida [...]. Ahora nos acordamos y nos duele el alma [...]. La Iglesia debería pedir perdón de rodillas [...]. Se nos tildaba que éramos brujos, que éramos hechiceros, que éramos diableros, cosa que no era cierto (entrevista con Miguel Ángel Calixto, Aquismón, San Luis Potosí, 17 de noviembre de 2014).
La memoria histórica alimenta la división, a pesar de que el encuentro con nuevos lenguajes y formas de relacionarse son una necesidad, por voluntad propia o ajena. En efecto, la voz del diablo se presentó en los juicios inquisitoriales, y como dice Miguel, se mostró desprecio hacia quienes eran considerados brujos o hechiceros (Gallardo, 2011). Para él queda pendiente el perdón, a pesar de que en la actualidad la Iglesia católica es una de las instituciones que más favorece las tradiciones indígenas y muchas veces impulsa la medicina herbolaria considerada tradicional. En los altares y rituales de curación, las imágenes de santos y los rezos católicos son elementos cruciales del proceso de sanación; mas no se trata de un sincretismo cultural, como quiero demostrar, pues ello supone la comprensión mutua entre formas de vida distintas, lo cual no es factible en tanto que los juegos de lenguaje que dan sentido a una forma de vida se conjugan en el mundo indeterminado del significado (Wittgenstein, 1975; Jacorzynski, 2008: 283). Utilizar imágenes y rezos católicos en un contexto ajeno a la liturgia del catolicismo obedece a que los curadores indígenas han sabido reconocer en el lenguaje religioso de herencia católica un elemento común con el lenguaje religioso intrínseco en toda curación espiritual. Esto es, se comulga, pero no se predica la religión católica, aun cuando algunos elementos del catolicismo son parte fundamental en las curaciones de tradición Tének.

El sincretismo supone lo contrario (Marzal, 2002: 195), que al utilizar imágenes católicas en rituales Tének se predica la religión católica mezclada con significados y prácticas propios de los Tének. En un sentido estricto, lo que se presenta como una mezcla o fusión es de hecho una posible confusión. La religión católica no es compatible con la tradición Tének en tanto que son lenguajes distintos, con reglas gramaticales distintas. Mientras más se adopta la liturgia católica para curaciones, por decir, de espanto, lo que vemos es la desaparición de la tradición Tének en los rituales de curación. Así, la idea 
de sincretismo es equívoca pues elimina a priori las contradicciones que presentan juegos de lenguaje distintos que adquieren sentido en formas de vida que no se corresponden entre sí. La apropiación de elementos cristianos como parte de la tradición Tének no supone comprensión mutua sino, en todo caso, una respuesta de carácter coyuntural a la necesidad social de encontrar un modo de supervivencia cultural.

La narrativa de Miguel es, por lo tanto, parcial, pues la idea del mal es necesaria para que la del bien adquiera sentido. Aun cuando la Santa Inquisición castigó con dureza a curanderos y hechiceros, no se puede descartar que entre la población Tének del periodo colonial no hubiera prácticas vinculadas al mal y en cierto modo a la hechicería. La probabilidad de que hayan pagado justos por pecadores ante el prejuicio fundamental hacia las formas de curación indígenas es el reclamo histórico que Miguel plantea. El problema tiene sustento, pues se cuestiona la posibilidad de comprensión mutua, dado que se aplicó la fuerza para modificar la forma de vida tradicional indígena, por ser considerada superchería. La idea de sincretismo no implica mutua comprensión desde el origen, sino la reacción a la dominación para sobrevivir en términos culturales e identitarios.

En las prácticas de curación entre los Tének existe un elemento fundamental e intrínseco a toda forma de atención: el lenguaje religioso, que para los curadores de la OSSMIT consiste en un misterio que pocos pueden comprender o que puede ser incomprensible. Quienes tienen la facultad de curar enfermedades actúan en el terreno del misterio que, en ocasiones, no tiene una explicación racional. Para Liberio Flores, vicepresidente de la OSSMIT, el misterio consiste en una serie de secretos que le son revelados sólo a quienes tienen el don de curar: "[son] secretos que hay para liberar a gente de malos espíritus. Un niño que llora y llora, creen que tiene ojo pero no se alivia de eso, es porque un niño es sensible a otro espíritu y puede ser un espíritu malo" (entrevista con
Liberio Flores, El Mirador, Aquismón, San Luis Potosí, 2 de diciembre de 2014).

La interacción simbólica con espíritus malignos es de hecho tema bien conocido entre los estudios de enfermedades de grupos amerindios (Lozoya y Zolla, 1983). En el caso de la sierra de Aquismón, destaca que los espíritus se distinguen de las energías que se manifiestan como aires y que pueden generar enfermedades. Existen tipos de espíritus y tipos de energías, conceptos genéricos para hablar sobre padecimientos vinculados a la noción de misterio. Un mal aire, por ejemplo, "es una energía que se mueve por el aire, un muerto [humano], un animal muerto, una escoba de barrida espiritual tirada en el camino" (entrevista con Liberio Flores, El Mirador, Aquismón, San Luis Potosí, 2 de diciembre de 2014).

La idea de que sea un muerto quien provoque un mal aire no se relaciona, en este caso, con la presencia de un espíritu proveniente de un reino del inframundo, sino con la energía que queda en el lugar donde falleció una persona. La manera en que el aire mueve esas energías y cómo éstas entran y se instalan en el cuerpo de una persona y provocan una enfermedad es parte del misterio. No existe una explicación racional, sólo sucede, pero se conoce la cura, que consiste en rezos, barridas con escobas espirituales hechas de yerbas y limpias con huevo de gallina. Para curar el espanto:

Es necesaria la sudoración de la persona que se va a curar. El líquido de la bilis debilita al paciente. Entonces debe estar encobijado, con yerbas hay tratamiento. Entonces se hacen rezos y se quema copal en cruz, se pone en todas las coyunturas del cuerpo. Entonces hay que hacer una limpia con escoba, en día que sea viernes, y se reza la oración a La Magnífica (entrevista con Liberio Flores, El Mirador, Aquismón, San Luis Potosí, 2 de diciembre de 2014). ${ }^{3}$

3 Esta oración surge del Evangelio de Lucas y tiene como contexto la Visitación de María a Isabel. 


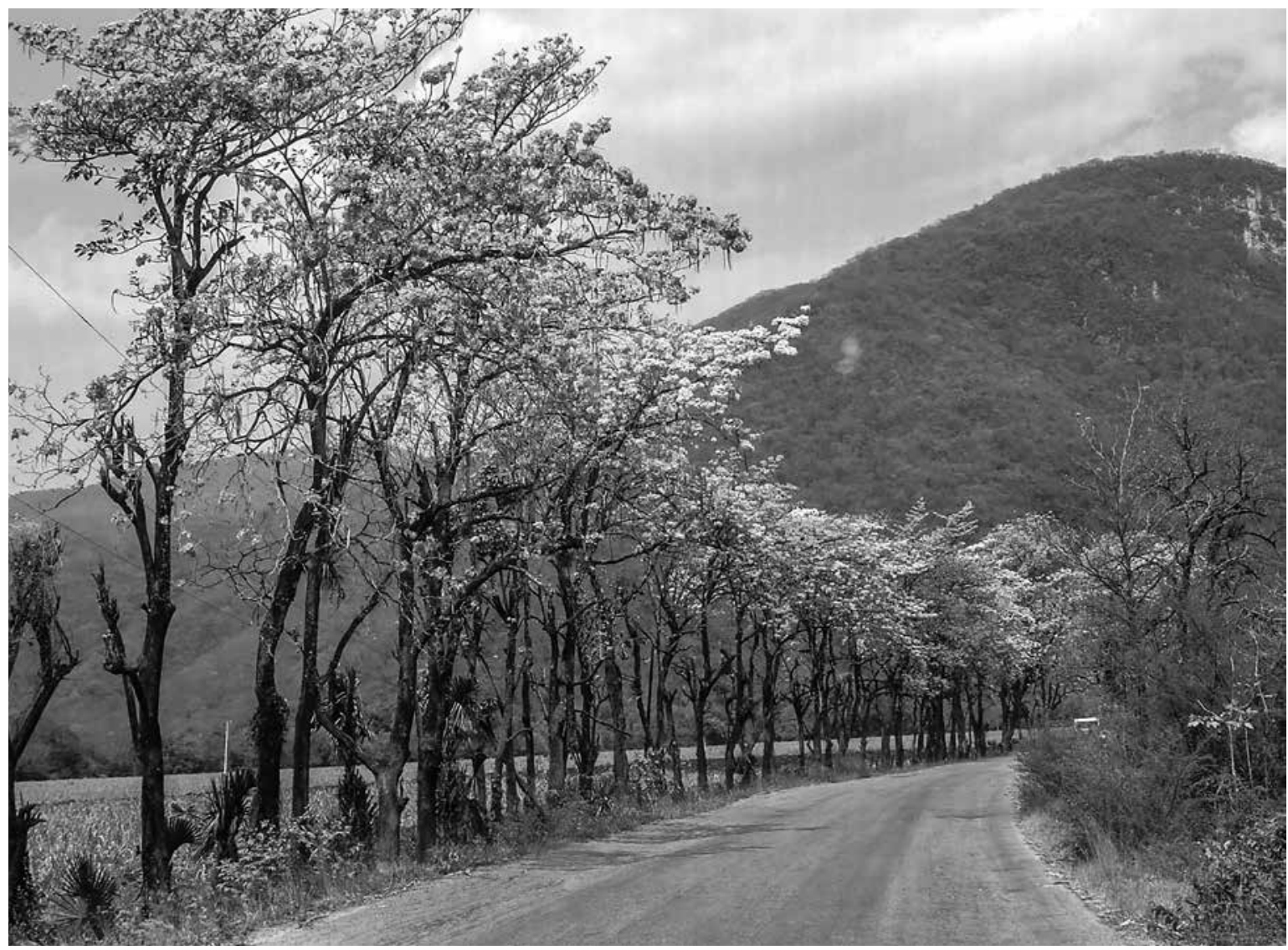

LUCY NiETo Palo de rosa en la Huasteca potosina, enero de 2015.

¿Es la oración a La Magnífica parte del misterio? Desde la perspectiva de Liberio y de quienes la utilizan para curar el espanto, sí. El uso y significado de la oración adquiere un matiz particular que no tiene que ver propiamente con la religión católica ni con su práctica, mucho menos con la idea de llevar vida religiosa. En todo caso, sirve como herramienta para un ejercicio de curación espiritual que, de manera paradójica, encuentra su explicación en términos de la medicina hipocrática al utilizar el concepto de bilis. Entonces, ¿cómo puede ser el espanto un padecimiento considerado tradicional indígena, explicado mediante conceptos de la medicina hipocrática y curado con ayuda de una oración cristiana en el contexto del misterio Tének?
Como sugería, al contrario de la idea del sincretismo, en realidad todo es producto de una confusión que se ha naturalizado con el tiempo, por el hecho de haber perdido una forma de vida tradicional y buscar otra que no se sabe cuál pueda ser, o bien, que es imposible recuperar. En ese tránsito, la necesidad de negociación con instituciones externas y la búsqueda de fundamentación de instituciones paralelas cuestionan la propia práctica de lo que podría considerarse tradición Tének. De aquí se desprende que, en el interior de las comunidades indígenas, en este caso de la Huasteca potosina, exista una división social caracterizada por el poder de quienes logran sostener instituciones que les permiten aprender nuevos lenguajes, que adaptan a intereses de carácter político 
no partidista, como sucede con la OSSMIT. Aún más interesante es el hecho de querer defender una forma de vida tradicional que ha perdido sus sedimentos originales. A la luz del impacto ontológico, lo que se demuestra es que, como práctica cotidiana, las comunidades indígenas están en la búsqueda de una forma de vida de manera permanente, porque la identidad indígena atraviesa una crisis difícil de solventar.

No queda más que seguir el camino de la exploración constante y aspirar a que, en la interacción de sociedades culturalmente plurales, se creen espacios en los que el diálogo y la comprensión mutua sean prioridad. Sin embargo, parece que no lograremos fomentarlos más si no partimos de: a) el reconocimiento de las crisis de las tradiciones como un proceso natural de todo grupo social, y b) que las fusiones o mezclas culturales no suponen ni favorecen la comprensión mutua entre lenguajes y tradiciones distintos, sino que provocan alteraciones que afectan de manera negativa cuando no se acepta con naturalidad el punto anterior. Si se sigue esta lógica, pueden alcanzarse conclusiones que ayuden a explicar la crisis de la tradición Tének. Primero, la alteridad de los significados, prácticas sociales y formas de organización en las comunidades Tének propician que la tradición carezca de sentido si se consideran sus rasgos más originales en contraste con la situación actual. Segundo, la idea de sincretismo, como la interculturalidad, implica un referente tradicional Tének, como elemento estático en el tiempo, que además posee la cualidad de fusionarse en equilibrio con otro elemento estático, es decir, una tradición distinta por completo, por lo que estas teorías, si bien pueden ser útiles para sostener algunas posturas políticas, en el fondo favorecen más la confusión y la crisis de la tradición. Por lo tanto, los representantes de la OSSMIT viven en una confusión permanente, pues buscan reivindicar una forma de vida tradicional en un contexto en el que sólo puede existir de manera parcial, y mantienen una posición que se opone a otras formas de vida y organización social. Se asume, a su vez, que son parte de un mundo que empieza a carecer de fronteras socioculturales.

La postura de la OsSMIT es defender una tradición que pocas veces opera en el marco de la tradición Tének y más bien se adapta a otras que dejan de ser indígenas excepto porque quienes las practican son indígenas y buscan que lo tradicional indígena se apegue al ideal de la tradición, para que, en la búsqueda de reconocimiento externo, no les afecte otro tipo de prácticas que se consideran en efecto tradicionales indígenas y que no se corresponden con los valores de la OSSMIT, por ejemplo, los curanderos que trabajan en el marco de la brujería y la magia negra, a diferencia de quienes curan padecimientos como el espanto con ayuda de limpias y oraciones católicas, como Liberio, sin recurrir a diagnósticos del ocultismo o a desenterrar objetos estilo vudú, de uso común en la Huasteca potosina.

\section{La distinción entre médicos indígenas tradicionales y curanderos}

La oposición ellos/nosotros no es tan binaria como parece. También existe una diferenciación profunda con curanderos que trabajan al margen de la organización y que de manera ocasional incurren en prácticas que no se consideran propias de la tradición Tének. Hay dos aspectos que distinguen con claridad a los médicos indígenas tradicionales de los curanderos no organizados: a) el vínculo con personas e instituciones externas al mundo tradicional indígena, y b) el grado de autenticidad en relación con la tradición indígena.

Si se considera que el curanderismo es el universo de prácticas vinculadas a la atención a la salud en la tradición Tének, con base en elementos históricos, los médicos indígenas tradicionales son, de hecho, curanderos y viceversa (Gallardo, 2008). Sin 
embargo, la distinción entre curanderos y médicos indígenas tradicionales adquiere sentido cuando los integrantes de la OSSMIT abogan por el rescate de una tradición que avanza hacia la curación del cuerpo y el espíritu en términos de una energía positiva, a diferencia de la brujería y la hechicería, que trabajan con energía negativa. Es decir, los médicos indígenas tradicionales buscan revalorar los aspectos positivos del curanderismo en relación con la tradición Tének, mientras que los curanderos no organizados, que trabajan por su cuenta, incorporan prácticas ajenas a lo que la OSSMIT considera parte de sus metas y objetivos como asociación. Así, el simple hecho de que unos estén organizados y otros trabajen de manera independiente les hace establecer una diferencia sustantiva en términos de la intencionalidad de sus prácticas.

Los médicos indígenas tradicionales buscan reconocimiento externo con el propósito de equiparar la medicina alópata en el ámbito local. Establecen diálogos con personal del sector de salud pública para echar a andar una estrategia de atención en una relación de enseñanza y aprendizaje con la población en general, mediante huertos medicinales de traspatio, para lo cual solicitan apoyo gubernamental, hasta ahora no recibido. Los curanderos independientes, en cambio, no demandan el reconocimiento externo ni tienen intención de compartir saberes con la población lega, por decirlo de algún modo. Los médicos indígenas tradicionales, al menos la cúpula de la OsSMIT, en cambio, persigue un acercamiento con sectores externos. Los médicos indígenas tradicionales organizados han marcado la distinción con los curanderos y se han apropiado de las categorías "médico" — quizá por la misma necesidad de reconocimiento externo - y "tradicional" para intentar recuperar costumbres y tradiciones propias. Pero la relación con agentes externos no va más allá del reconocimiento en términos de advertir y tratar de respetar la coexistencia de prácticas diversas de atención a la salud. ${ }^{4}$
El sector salud procura que los médicos indígenas tradicionales se capaciten en talleres de salud intercultural y que se involucren como avales ciudadanos en las clínicas rurales. Los médicos residentes, quienes defienden su profesión por el reconocimiento social que otorga la universidad, las más de las veces consideran esta participación como algo ajeno a la medicina científica. Esto reduce el número de médicos indígenas tradicionales que aceptan capacitarse y ser avales para que se reconozca su presencia, y reciban respeto y tolerancia, lo cual no impacta en la realización de diagnósticos y tratamientos. No obstante, la OsSMIT busca otro tipo de reconocimiento, que trasciende su presencia en las clínicas en estos términos, y procura que tanto la comunidad de médicos alópatas y el personal de salud, entre otros sectores, revaloren el ejercicio de la medicina tradicional indígena como entidad que reivindica valores culturales con una historia de largo alcance. A su vez, se opone a quienes, siendo indígenas, no siguen los valores de la historia cultural que les es propia, es decir, considera que hay indígenas más verdaderos y genuinos que otros, puesto que los últimos han abandonado la tradición, y hay curanderos que realizan prácticas que no corresponden con la noción de salud en los términos de la tradición indígena. Se considera que las prácticas de las que se han apropiado los curanderos que no siguen la tradición se han heredado del mestizaje, por lo tanto, carecen de valor en el marco tradicional indígena.

$4 \quad$ En la región existe otra asociación de médicos indígenas tradicionales que ofrece sus servicios una vez por semana en las instalaciones de la CDI, situadas en el municipio de Tancanhuitz de Santos, la Organización de Terapeutas Indígenas Tradicionales, Canhuitz, A. C. Dado que mi trabajo de campo se concentró en el municipio de Aquismón, no tengo datos de esta organización. Llama la atención, no obstante, que utilice el concepto de terapeuta y no de médico. 
Por ejemplo, la música y danza ritual, que implica el consumo de alcohol, tiene un sentido curativo en la costumbre Tének. La práctica se vincula a la salud tanto personal como social, pero si un curandero ve el ritual como una fiesta en la que la persona baila y se embriaga, sin comprender la relación de la música y la danza con la salud, entonces ya no es un curandero verdadero y no puede ser médico indígena tradicional. El señalamiento es sutil pero importante, pues lo que puede ser para alguien un ritual de danza y música con efectos positivos para la salud, para otra persona puede causar, por el contrario, un desgaste energético, y como consecuencia, enfermedad. Considerar un ritual de música y danza una práctica de curación o una fiesta es una de las distinciones entre conocer o no los misterios del saber indígena en relación con la salud.

En ese sentido, los curanderos falsos, que no siguen la tradición como deberían, dejan de comprender el sentido verdadero de la curación. Si no son médicos indígenas tradicionales reconocidos por la comunidad y el CDMIT, y se sospecha que incurren en conductas inapropiadas, no pueden formar parte de la OSSMIT. La conducta inapropiada es un signo de debilidad, pues además de que no se siguen los cánones de la tradición indígena, se corre el riesgo de no fomentar la salud y multiplicar los daños, los cuales se asocian a la brujería.

De ahí surge la idea de que hay curanderos que hacen daño, aunque habría que distinguir entre quienes lo hacen de manera intencional y las consecuencias de intentar ejercer un conocimiento que en realidad no se posee. La conducta inapropiada es un indicador importante en este sentido, aunque sólo los especialistas o los profesionales locales, en el marco de la tradición indígena, hacen esa distinción; no así la población en general. Lo novedoso es que los curanderos considerados malos son los que no siguen la tradición indígena y se asocian a comportamientos inadecuados, contemplados como parte de su práctica como curanderos. La conducta inadecuada no sólo radica en no seguir la tradición indígena como se debe, sino en asumir un papel social sin tener una verdadera vocación o sin haber recibido el don de curar:

Miguel (M): De que hay curanderos malos, sí los hay. En el sentido de que [...] ven a aquel cojeando, que no anda bien, que no salió a trabajar, y también aquel dice, el curandero: "no [pues] yo también le voy a echar a la curada", pero también es peligroso. Si viene una persona que no sabe, si hasta uno que está preparado... Es como un sacerdote, si no está preparado, viene una persona muy mala, con mal aire, con brujería, la curas; a lo mejor se va a componer tantito, pero el mal te brincó a ti. Y aquél se curó, pero tú te moriste. Entonces hay curanderos malos, sí los hay, porque me han venido a platicar que fulano, y que llega aquí y que hace esto y hace esto otro y así. Pero eso no se hace. Pero bueno, ahora él lo hace. Porque lo malo corre de volada, el chisme, diría la gente. La gente no [debería permitirlo], porque, ya borracho, como que se propasa con el paciente. Sí, eso sí nos duele a nosotros y nos indigna, nos duele que esos cuates hagan eso. Yo les he dicho: "bueno, si te hizo eso, bueno, denúncialo, no te quedes así, pon una denuncia”, porque uno está para ayudar. El enfermo viene buscando ayuda, no viene tampoco a que lo manosee uno, a que se le propase; por lo que entonces, lo que le contaron a usted, sí es cierto.

Daniel (D): ¿Pero entonces la OSSMIT trata de luchar contra eso, para evitar que se contamine?

M: Sí, aquí hay un reglamento, tenemos aparte el acta constitutiva. Aquí todo el médico que llegue, se le recomienda a la gente que sea ultrajada o que se propase el médico [tradicional] con el paciente, que venga aquí a dejar la queja. Aquí se levanta un acta, la va a firmar, y de aquí se turna a la agencia del ministerio público. Y en caso que sea cierto, esa persona está fuera de la organización [...]. Hay un reglamento, la organización no se hizo para eso [...]. 


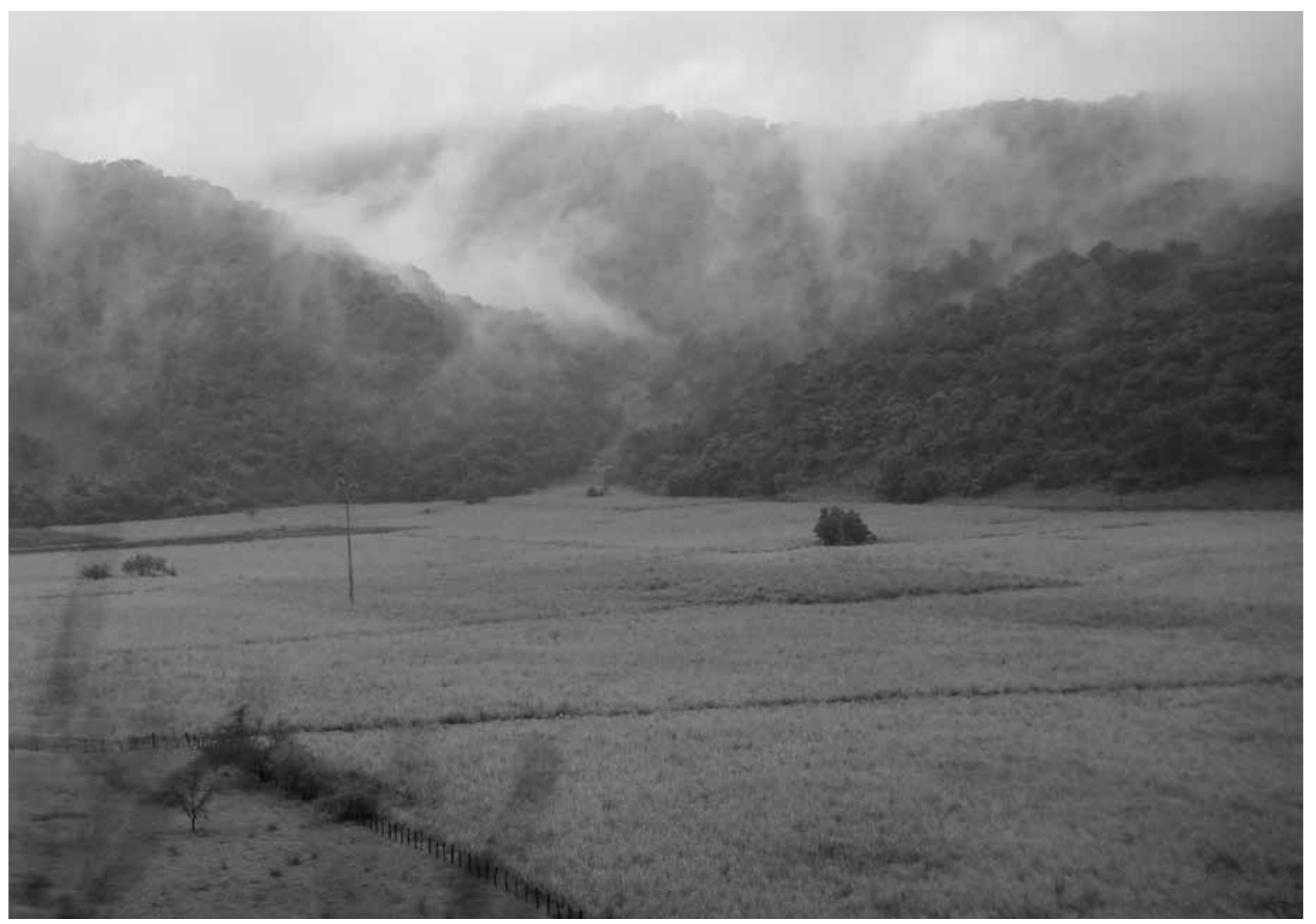

LUCY NIETO - Paisaje en la carretera de Ciudad Valles, Huasteca potosina, junio de 2008.

Lo hemos dicho y a través de la radio también lo hemos dicho. Y cualquier persona que sea atendida por un médico que pertenezca al Consejo [CDMIT], a la OSSMIT [y que no haga correctamente su trabajo], que pongan la denuncia directamente aquí, a la sede del Consejo, trae sus testigos, la va a firmar, y se turna a la agencia del ministerio público.

D: ¿Y las danzas que se hacen son frecuentes o tienen fecha especial, o se hacen para alguna curación? M: Sí, se hace para curación, la música es sagrada [...]. Tenemos el bastón de mando, conocemos qué es el bastón de mando, porque ahora, totalmente, los indígenas, completamente se perdió. Perdieron, perdimos, qué es el bastón de mando, qué significa. El bastón de mando tiene una grande jerarquía, es el gobierno indígena. Significa organización social, poder, honor, justicia, mando, su significado de las siete bandas, sí, siete bandas, son los siete colores del arco iris. Ahora veo yo que los indígenas, al candidato [político partidista] le dan una varita, como un bastón de mando, ni el que lo dio sabe qué le dio, qué significa, menos el que lo recibe. Lo peor es que al otro día, a los cinco días, ahí está tirado, la varita aparece en el basurero... Mira, ahí está el bastón de mando que dieron... No, perdieron el significado [...]. Claro, al bastón de mando se le hace su ceremonia, aquí nosotros tenemos el bastón, ya está viejito, pero lo cuidamos porque sabemos lo que es para nosotros (entrevista con Miguel Ángel Calixto, Aquismón, San Luis Potosí, 17 de noviembre de 2014). 
El testimonio de Miguel, no sólo como presidente de la OSSMIT sino como autoridad en turno, es claro y contundente: la diferencia entre los verdaderos médicos indígenas y los curanderos que no forman parte de la organización consiste en el conocimiento o desconocimiento de las costumbres y tradiciones, del significado de las acciones y los símbolos que los representan, como el bastón de mando.

\section{Conclusiones}

La disyuntiva entre buscar una forma de vida o mantener otra considerada tradicional indígena parece una condición natural en estos tiempos de pluralidad social y cultural y de flujos globales, pero se corre el riesgo de actuar en el terreno de la confusión. Superarla es un desafío constante, pero la elección de una forma de vida personal se define por las acciones que implican seguir determinados lenguajes y sus reglas gramaticales. El problema surge cuando los lenguajes que dan sentido a la forma de vida elegida no corresponden con las prácticas sociales que se ponen juego. De esta manera, si el lenguaje de las curaciones indígenas tradicionales tiene como regla seguir una tradición que se encuentra en crisis, éstas tienden a modificarse o incluso a desaparecer, y se les considera tradicionales indígenas porque son indígenas quienes las realizan.

La confusión se acrecienta con teorías como el sincretismo o la interculturalidad, pues más que reivindicar una manera de ver y comprender el mundo según tradiciones ideales que se sostienen por la memoria histórica y cultural, pretenden fusionarlas con otras. ${ }^{5}$

Por mencionar un ejemplo, para el grueso de la población Tének, determinados niveles de glucosa en la sangre y los medicamentos para controlar la diabetes no tienen mayor significado, excepto cuando se recurre a la clínica como forma de diagnóstico en una lógica distinta a la de la ciencia médica, para confirmar si se es objeto de un trabajo de brujería, al valorar los efectos de los medicamentos en los padecimientos. De modo que se aceptan los diagnósticos y los fármacos, pero no se valora ni se comprende el quehacer médico alópata. De manera paradójica,

El tema de la interculturalidad como elemento que acrecienta la confusión social y cultural es una afirmación a priori, pues la aclaración de este aspecto merece que se le dedique un artículo completo. Parece injusto el vacío conceptual que indica que la interculturalidad y el sincretismo, si bien han sido herramientas conceptuales útiles, representan una trampa analítica que desdibuja la imposibilidad de comprensión mutua entre dos o más partes que sostienen como imagen del mundo un conjunto de conceptos que pierde su sentido original en los juegos de lenguaje de una forma de vida distinta. La interculturalidad ha abonado la reflexión académica y ha ganado, mediante el ejercicio intelectual, el reconocimiento a la diversidad y la revaloración de conocimientos locales que se suscitan al margen de la producción de conocimiento académico, en este caso de la ciencia médica. Sin embargo, aun cuando la interculturalidad ha señalado la negociación constante que implica la interacción de formas de vida distintas, en la operación de clínicas rurales se observa su reducción a nociones como respeto y tolerancia, entre otras maneras de relacionarse que toman en cuenta los derechos humanos universales, y los diagnósticos y formas de atención se definen de manera estricta con lenguaje científico y los pacientes y curadores locales juegan un papel pasivo ante el ejercicio clínico. Para ahondar en este tema, véase Flores (2017). Cabe señalar que la interculturalidad como herramienta conceptual ha contribuido al diseño de políticas internacionales y nacionales en áreas estratégicas como salud y educación. Coincido con Menéndez cuando sugiere que "los estudios interculturales han excluido de los análisis las dimensiones diferenciales de raza, etnicidad, género, clase, entre otros vectores que favorecen la desigualdad" (2006: 57). La interculturalidad -en tanto supone la comprensión mutua y la creación de espacios de equidad a pesar de la diversidad- encarna una posición romántica en la que tienen cabida la reciprocidad, el intercambio, las relaciones simétricas, sin tomar en cuenta que los juegos de lenguaje de la ciencia, la atención a la salud en las clínicas rurales y la política pública de salud difieren de otras prácticas de curación, por lo que no hay posibilidad de intercambio sino, en todo caso, una alteración significativa, en la que conceptos que dan sentido a una imagen del mundo se pierden y carecen de sentido. 
en el ámbito local es frecuente que se piense que los médicos y enfermeras no saben diagnosticar ni curar bien, pero es deseable contar con médicos residentes hasta en las localidades más pequeñas. En ese tránsito de una lógica a otra, la OSSMIT parece luchar para modificar tanto la visión del grueso de la población Tének, que considera que está embrujada porque los medicamentos alópatas no surten efecto, como de los médicos alópatas, quienes al parecer no valoran el trabajo de los médicos indígenas tradicionales, capaces de producir medicinas y hacer curaciones en ocasiones más efectivas que los medicamentos alópatas.

La OSSMIT va contra la corriente. En la intención de mantener una forma de vida que no corresponde del todo a los lenguajes puestos en juego en los espacios de interacción social en el ámbito local, prevalece la confusión por la crisis que se genera en el ideal de lo tradicional indígena.
Esto deviene en que, más que mantener una forma de vida definida y socialmente reconocida, ésta se busca de manera permanente. Por lo tanto, la forma de vida de quienes desean reivindicar las tradiciones indígenas en su sentido original consiste en buscar una forma de vida de manera constante. Queda pendiente analizar el impacto de esto en un plano ontológico y existencial, en escala personal, en otros artículos quizá, bajo el concepto general de antropología de la mente. Por el momento, queda definido que los indígenas tradicionalistas, para defender sus ideales y forma de vida, han convertido en su necesidad las necesidades de las instituciones del Estado, como la CDI o las clínicas interculturales del programa IMSs Oportunidades, a las cuales se oponen en el fondo, pero tampoco muestran apertura para asociarse con sectores indígenas que no son fieles a los valores tradicionales. Entonces la crisis prevalece y se agudiza. D

\section{Bibliografía}

Aguirre Beltrán, Gonzalo, Eduardo L. Menéndez, Carlos Viesca, Xavier Lozoya y Leonel Durán, 1987, Medicina tradicional y atención primaria. Ensayos en homenaje a Gonzalo Aguirre Beltrán, Centro de Investigaciones y Estudios Superiores en Antropología Social, México.

, 1994, Obra antropológica, V: Programas de salud en la situación intercultural, Fondo de Cultura Económica, México.

Alarcón Lavín, Roberto, 2010, "La biopiratería de los recursos de la medicina indígena tradicional en el estado de Chiapas, México. El caso ICBG-Maya”, en Pueblos y Fronteras, vol. 6, núm. 10. Disponible en línea: <http://www.pueblosyfronteras.unam.mx/index.php/index. php/pyf/article/view/149/149>.

Ayora, Steffan, 2002, Globalización, conocimiento y poder: médicos locales y sus luchas por el reconocimiento en Chiapas, Universidad Autónoma de Yucatán/Plaza y Valdés, México.

Campos Navarro, Roberto, 1996, “Curanderismo, medicina indígena y proceso de legalización”, en Nueva Antropología, núms. 52-53, pp. 67-87. Disponible en línea: <http://www.juridicas.unam.mx/publica/librev/rev/nuant/cont/52/cnt/cnt3.pdf>.

Cázares, Jessica, 2006, Actividad en Drosophila melanogaster y Sitophilus zeamais (insecta) de aceites esenciales de plantas usadas para combatir insectos en Hidalgo, tesis de licenciatura en biología, Universidad Autónoma del Estado de Hidalgo, Pachuca. Disponible en línea: <http://www.uaeh.edu.mx/docencia/Tesis/icbi/licenciatura/documentos/Actividad\%20en\%20drosophila.pdf>.

Flores Albornoz, Daniel, 2017, (Des)encuentros de la ciencia médica con las prácticas de curación en la Sierra de Aquismón, SLP, tesis de doctorado en antropología, Centro de Investigaciones y Estudios Superiores en Antropología Social, México.

Foster, George, 1958, Problems in Intercultural Health Programs, Social Science Research Council, Nueva York.

Freyermuth, Graciela, 1993, Médicos tradicionales y médicos alópatas. Un encuentro difícil en los Altos de Chiapas, Gobierno del Estado de Chiapas/Instituto Chiapaneco de Cultura/Centro de Investigaciones y Estudios Superiores en Antropología Social, Tuxtla Gutiérrez. 
Gallardo, Patricia, 2008, Curanderos y medicina tradicional en la Huasteca, Programa de Desarrollo Cultural de la Huasteca/Instituto Veracruzano de la Cultura, México.

__ , 2011, "La transgresión al ideal femenino cristiano y una acusación por brujería en Valle del Maíz", en Revista Estudios de Historia Novohispana, núm. 44, pp. 77-111.

Jacorzynski, Witold, 2008, En la cueva de la locura: aportación de Ludwig Wittgenstein a la antropología social, Centro de Investigaciones y Estudios Superiores en Antropología Social, México.

López Austin, Alfredo, 1989, Cuerpo humano e ideología. Las concepciones de los antiguos nahuas, 2 vols., Universidad Nacional Autónoma de México, México.

Lozoya, Xavier, 1988, La medicina tradicional en México: experiencia del programa Imss-Coplamar, folleto, Instituto Mexicano del Seguro Social, México.

Lozoya, Xavier y Carlos Zolla (eds.), 1983, La medicina invisible. Introducción al estudio de la medicina tradicional de México, Folios Ediciones, México.

1984, "Medicina tradicional en México", en Boletín de la Oficina Sanitaria Panamericana, abril, pp. 360-364. Disponible en línea: <http://hist.library.paho.org/Spanish/BOL/v96n4p360.pdf>.

Lumholtz, Carl, 2017, “Un explorador del siglo xix. Carl Lumholtz”, galería fotográfica, Fototeca Nacho López, Comisión Nacional para el Desarrollo de los Pueblos Indígenas, México. Disponible en línea: <https://www.gob.mx/cdi/galerias/un-explorador-del-siglo-xix-carllumholtz>

Marzal, Manuel, 2002, Tierra encantada. Tratado de antropología religiosa de América Latina, Trotta/Pontificia Universidad Católica del Perú, Madrid.

Menéndez, Eduardo L., 1981, Poder, estratificación social y salud. Análisis de las condiciones sociales y económicas de la enfermedad en Yucatán, Centro de Investigaciones y Estudios Superiores en Antropología Social, México.

- 1987, “Medicina tradicional, atención primaria y la problemática del alcoholismo”, en Gonzalo Aguirre Beltrán, Eduardo L. Menéndez, Carlos Viesca, Xavier Lozoya y Leonel Durán, Medicina tradicional y atención primaria. Ensayos en homenaje a Gonzalo Aguirre Beltrán, Centro de Investigaciones y Estudios Superiores en Antropología Social, México, pp. 19-58.

__. 1994, “La enfermedad y la curación. ¿Qué es la medicina tradicional?”, en Alteridades, núm. 7, pp. 71-83.

2006, “Interculturalidad, 'diferencias' y antropología 'at home”, en Gerardo Fernández (coord.), Salud e interculturalidad en América Latina. Antropología de la salud y crítica intercultural, Abya-Yala, Quito, pp. 51-66.

Sahagún, Bernardino de, 1829, Historia general de las cosas de Nueva España, t. 1, Imprenta del Ciudadano Alejandro Valdés, México. Disponible en línea: <http://cdigital.dgb.uanl.mx/la/1080012524_C/1080012524_T1/1080012524_MA.PDF>.

Villa Rojas, Alfonso, 1992, Los elegidos de Dios. Etnografía de los mayas de Quintana Roo, Consejo Nacional para la Cultura y las Artes/ Instituto Nacional Indigenista, México.

Wittgenstein, Ludwig, 1975, Sobre la certeza, Gedisa, Barcelona.

Zolla, Carlos, 2011, "Del Imss-Coplamar a la experiencia del Hospital Mixto de Cuetzalan. Diálogos, asimetrías e interculturalidad médica”, en Arturo Argueta Villamar, Eduardo Corona y Paul Hersch Martínez (coords.), Saberes colectivos y diálogo de saberes en México, Universidad Nacional Autónoma de México-Centro Regional de Investigaciones Multidisciplinarias/Universidad Iberoamericana Puebla, Cuernavaca, pp. 201-231. Disponible en línea: <https://www.crim.unam.mx/web/sites/default/files/Saberes_Parte_I.pdf>.

\section{Entrevistas}

Miguel Ángel Calixto, Aquismón, San Luis Potosí, 17 de noviembre de 2014.

Liberio Flores, El Mirador, Aquismón, San Luis Potosí, 2 de diciembre de 2014. 